\title{
A Wild Cajanus scarabaeoides (L.), Thouars, IBS 3471, for Improved Insect-Resistance in Cultivated Pigeonpea
}

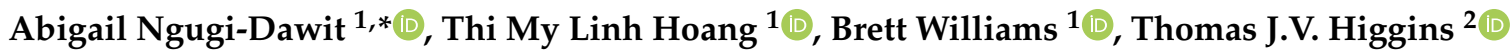 \\ and Sagadevan G. Mundree ${ }^{1, *}$ \\ 1 Centre for Agriculture and the Bioeconomy, Institute for Future Environments, Queensland University of \\ Technology (QUT), 2 George Street, Brisbane, QLD 4000, Australia; 1t.hoang@qut.edu.au (T.M.L.H.); \\ b.williams@qut.edu.au (B.W.) \\ 2 Commonwealth Scientific and Industrial Research Organisation (CSIRO), Agriculture and Food, \\ Canberra 2601, Australian Capital Territory, Australia; Tj.Higgins@csiro.au \\ * Correspondence: a.dawit@hdr.qut.edu.au (A.N.-D.); sagadevan.mundree@qut.edu.au (S.G.M.); \\ Tel.: +61-731-388-386 (S.G.M.)
}

Received: 14 February 2020; Accepted: 23 March 2020; Published: 3 April 2020

\begin{abstract}
Cajanus scarabaeoides (L.), Thouars, is the closest wild crop relative of cultivated pigeonpea, Cajanus cajan (L.), Millspaugh. This wild pigeonpea has several insect-resistance mechanisms, particularly to Helicoverpa armigera (Hübner). Estimated economic losses in the semi-arid tropics from $H$. armigera damage in pigeonpea are approximately two billion USD/year. Therefore, it is imperative to improve pest resistance in this crop. In this study, we investigated insect-resistance components in IBS 3471, a C. scarabaeoides accession, and explored the possibility of transferring resistance mechanism/s to cultivated pigeonpea. A detached leaf bioassay revealed that IBS 3471 has more effective antibiosis and antixenosis resistance mechanisms against $H$. armigera compared to the susceptible C. cajan variety, ICPL 87 . To further investigate the antibiosis resistance mechanism, we fed $H$. armigera larvae a heated and non-heated artificial diet supplemented with lyophilised IBS 3471 leaf powder. Incorporation of IBS 3471 leaf powder inhibited H. armigera larval weight and delayed larval development compared to larvae reared on diet supplemented with ICPL 87 leaf powder. The putative insect-resistance compounds in C. scarabaeoides were heat-labile. Proteomic analysis revealed higher levels of potential insecticidal proteins, namely lectin and cysteine proteinase inhibitor, in wild pigeonpea compared to the cultivated variety. Nutritional analysis and interspecific hybridisation experiments also indicated that IBS 3471 is a potential candidate for improvement of insect-resistance in pigeonpea. This study demonstrates that IBS 3471 has multiple resistance mechanisms against $H$. armigera, and they are transferable to cultivated pigeonpea.
\end{abstract}

Keywords: antibiosis; antixenosis; Cajanus cajan; Helicoverpa armigera; pigeonpea; pod borer; trichome; Cajanus scarabaeoides; insect resistance

\section{Introduction}

Pigeonpea (Cajanus cajan (L.) Millspaugh) is an important crop that sustains the livelihood of most people in the semi-arid tropics (SAT), where they depend on rain-fed agriculture [1]. It is grown worldwide and has an annual production approaching seven million tonnes per year [2]. Dry, mature seeds of pigeonpea are nutritionally rich in protein, carbohydrates, B-group vitamins, amino acids, calcium, fibre and iron [3]. Lack of high-yielding cultivars resistant to biotic stress is one of the major contributors for yield plateau and losses in pigeonpea, and the most important biotic stress is the insect pest, Helicoverpa armigera (Hübner), the pod borer [4]. H. armigera damage is a significant constraint in 
pigeonpea production with an estimated production loss of more than two billion USD in SAT, despite more than 500 million USD spent on insecticides annually [5].

C. scarabaeoides (L.) Millspaugh is one of the few wild relatives of pigeonpea that is sexually compatible with cultivated pigeonpea (C. cajan). It is highly drought and salinity tolerant, has a high grain protein content and displays strong resistance against insect pests. For these reasons, C. scarabaeoides represents a potential source of resistance to pod borer, pod fly, pod wasp and phytophthora blight in pigeonpea [5]. C. scarabaeoides has several resistance mechanisms against pod borer, such as antixenosis (non-host preference), antibiosis (harmful effect on insect biology) and non-preferential oviposition by its trichomes and exudates [3,6]. The characteristics of trichomes, including trichome type, orientation, density and length, present on a plant influence the damage that insect pests can cause in several crops [7]. Five types of trichomes (type A, B, C, D and E) are recognised in cultivated and wild pigeonpea [8]. The role of trichomes in insect defence is established in many plants, including tomato, Arabidopsis and pigeonpea [9-11].

Resistance to insect pests such as $H$. armigera in $C$. scarabaeoides varies considerably among accessions. Therefore, germplasm must be characterised and screened for insect-resistance [1]. Screening for resistance to $H$. armigera under natural conditions has limitations because of variation in the insect population [12]. The use of a detached leaf bioassay and an artificial diet supplemented with lyophilised leaf powder under uniform insect pressure at vegetative and flowering, or pod developmental stages, overcomes many of these problems [12].

There are several inducible defence mechanisms that plants activate in response to pathogen and herbivore injuries. Plants also encode numerous constitutive defence measures. Biologically active compounds such as protease inhibitors, amylase inhibitors and lectins play crucial roles in plant defence response against pests and pathogens [13-15]. Proteases, also called proteinases or peptidases, are enzymes that cleave protein peptide bonds. These enzymes are ubiquitous in nature and abundant in plants, animals and microorganisms, and as a result, they are crucial in many biological processes [16-18]. Plant protease inhibitors (PPIs) are involved in defensive responses against herbivores and inhibit insect digestive proteases [15,19]. PPIs ingested by the insect induce digestive enzyme overproduction, causing amino acid deficiencies that affect growth, decrease fecundity or cause death [20-22]. There have been several reports of the detrimental effects of different PPIs on insect growth and development, such as chickpea Kunitz trypsin inhibitor on pod borer larvae and potato leaf chymotrypsin/trypsin inhibitor II on Spodoptera exigua larvae [21,23,24]. PPIs are potential tools for improving not only the host plant's resistance mechanism, but also human nutrition, as many protease inhibitors are rich in cysteine and lysine, contributing to improved nutritional content [25]. To the contrary, many plants have considerable amounts of PPIs, and their anti-nutritional effects are substantially reduced by treatments such as soaking and cooking; hence, these have no lethal effects on humans [25]. Most known PPIs are from the Leguminosae, Solanaceae and Gramineae families [26].

There are several types of defence-related lectins. Transgenic tobacco expressing Orysata, (a mannose-specific jacalin-related lectin from rice), showed strong insecticidal activity against Spodoptera exigua, Myzus persicae and Acyrthosiphon pisum [27]. Transgenic tobacco and Indian mustard (Brassica juncea) expressing Allium sativum leaf agglutinin lectin (ASAL) displayed increased toxicity against hemipterans [28-30]. Rice lines with ASAL and Galanthus nivalis agglutinin (GNA) are more resistant to Nilaparvata lugens, Nephotettix virescens and Sogatella furcifera [31]. Studies on amylase inhibitors, using both enzymatic activity and feeding bioassay experiments, demonstrated roles for these proteins in plant defence against several insects [32,33]. For example, transgenic pea and azuki bean with bean $\alpha$-amylase inhibitor-I showed resistance against Bruchus pisorum, Callosobruchus maculatus and Callosobruchus chinensis [33-35].

In this study, we investigated the insect-resistance strategies of IBS 3471, an accession of C. scarabaeoides, including trichome structures and PPIs, and explored the possibility of transferring one or more of those factors to cultivated pigeonpea. 


\section{Materials and Methods}

\subsection{Plant Material}

IBS 3471 was selected out of 11 C. scarabaeoides accessions, based on a preliminary insect-resistance screening at the Queensland University of Technology (QUT), Centre for Agriculture and the Bioeconomy (CAB) laboratory (Supplementary Table S1 and Figure S1). ICPL 87, a high-yielding C. cajan variety, a universal susceptible check to $H$. armigera, was chosen as a control. All seeds used in this study were obtained from the Australian Grains Genebank (AGG) (Horsham, Victoria, Australia), except for the less susceptible ICPL 20338, the female parent in the interspecific hybridisation, which was obtained from the International Crops Research Institute for the Semi-Arid Tropics (ICRISAT), (Patancheru, Hyderabad, India). Mechanically scarified IBS 3471, ICPL 20338 and ICPL 87 seeds were germinated in Petri dishes $(90 \mathrm{~mm})$, with moist filter paper, in an incubator, at $36^{\circ} \mathrm{C}$. The germinated seeds were planted in Searles premium potting mix, in an environmentally controlled glasshouse $(27 \pm$ $1{ }^{\circ} \mathrm{C}, 13 \mathrm{~h}$ light and $11 \mathrm{~h}$ dark), at QUT Carseldine facilities, (Brisbane, Australia). Bamboo sticks were used to provide support for $C$. scarabaeoides accession, which has a climbing habit. No pesticide was applied to the plants during the experiments.

\subsection{Insect Culture}

H. armigera egg colonies were obtained from the Commonwealth Scientific and Industrial Research Organisation (CSIRO), (Narrabri, New South Wales, Australia). Eggs were hatched at $25^{\circ} \mathrm{C}$, and the neonate larvae were transferred to freshly prepared Stonefly Heliothis diet (Ward's scienceX), by mixing the powder diet with water-vinegar (19:1). Moths were fed on 10\% honey (diluted with water) and placed in a Sanyo Versatile environmental test chamber (Model MLR-350H, Japan) at $27 \pm$ $1{ }^{\circ} \mathrm{C}$, with $16 \mathrm{~h}$ light and $8 \mathrm{~h}$ dark. Larval growth instar stages were categorised as described in the Queensland government department of primary industries and fisheries guideline [36].

\subsection{Screening for Antibiosis and Antixenosis Defence Mechanisms in Wild and Cultivated Pigeonpea, Using Detached Leaf Bioassay}

Five $H$. armigera eggs were placed on young, freshly harvested and fully expanded first trifoliate leaves of IBS 3471, ICPL 87, ICPL 20338 and an $F_{1}$ interspecific hybrid (IBS 3471×ICPL 20338), in Petri dishes with moist filter paper, and replicated ten times. The dishes were placed in an environmentally controlled growth room, at $25 \pm 1{ }^{\circ} \mathrm{C}$, with $16 \mathrm{~h}$ light and $8 \mathrm{~h}$ dark. The leaves were replaced with freshly harvested leaves every $24 \mathrm{~h}$. First and second instar larvae of $H$. armigera were reared as groups, while larvae from the third instar and beyond were reared individually, to avoid cannibalism. The larval weights were recorded after eight days.

\subsection{Trichome Identification}

Scanning electron microscopy (SEM) was used to identify the types of trichomes on leaves and pods of wild and cultivated pigeonpea. Leaf samples were cut into three pieces, while for the pods, the epidermis was peeled. Both samples were flooded with $2.5 \%$ glutaraldehyde in $0.2 \mathrm{M}$ cacodylate buffer solution and soaked overnight in a fume hood. After $24 \mathrm{~h}$, the samples were rinsed three times with $0.2 \mathrm{M}$ cacodylate buffer. After each rinse, the samples were soaked for ten minutes. Samples were dehydrated, using graded ethanol $(\mathrm{EtOH})$ series, with each concentration step repeated twice, for $10 \mathrm{~min}$, before moving onto the next concentration, as follows; $50 \%, 70 \%, 90 \%$ and $100 \% \mathrm{EtOH}$. The last step was repeated three times, each for $15 \mathrm{~min}$. Dehydrated samples were mounted on SEM carbon tabs coated with gold, using Leica EM-SCD005 Sputter Coater, and placed on SEM stub holders and stored in a cool dry place, until the samples were analysed, using a Zeiss Sigma VP Field Emission SEM at 100× magnification. Each accession had three leaves and three pods, and each sample was scanned three times. 


\subsection{Screening for Antibiosis Defence Mechanism in Pigeonpea Using Artificial Diet Supplemented with Lyophilised Leaf Powder Bioassay}

The first fully expanded leaves of IBS 3471, ICPL 87, ICPL 20338 and an $F_{2}$ interspecific hybrid from self-pollinated interspecific $F_{1}$ (IBS 3471×ICPL 20338) were harvested from glasshouse-grown plants and transported to the laboratory on dry ice and stored at $-80^{\circ} \mathrm{C}$. Due to a limitation in the number of $\mathrm{F}_{1}$ interspecific hybrid plants, experiments for antixenosis and antibiosis bioassays using artificial diet supplemented with lyophilised leaf powder were carried out, using $\mathrm{F}_{2}$ interspecific hybrids. Leaves were freeze-dried for $72 \mathrm{~h}$, to minimize any changes in biochemical composition, using a Benchtop Pro with Omnitronics ${ }^{\mathrm{TM}}$ freeze dryer (VirTis SP Scientific, USA). The freeze-dried leaves were milled, using a Tube Mill Control (IKA Mills No. 0004180000, China) for $25 \mathrm{~s}$, at 25,000 rpm. The artificial diet was prepared by mixing the Stonefly Heliothis diet (Ward's ScienceX) powder (21.7 g), lyophilised leaf powder (3.3 g) and $100 \mathrm{~mL}$ of water-vinegar (19:1). A plain artificial diet (PAD) without lyophilised leaf powder was used as a control. To investigate whether potential inhibitors were heat-labile, the effects of heated and non-heated diets were assessed. For heating, the mixed diets were microwaved for $90 \mathrm{~s}$ (750W, Sharp Carousel R-5A12).

A moist paintbrush was used to place neonate H. armigera larvae into each well of a 32-cell rearing tray (RT32W, Frontier Scientific Services Agriculture, USA). The tray was sealed with a clear rearing tray Lid-4 Cells (RTCV4, Frontier Scientific Services Agriculture, USA) and placed in a Sanyo Versatile environmental test chamber (Model MLR-350H, Japan), at $26 \pm 1{ }^{\circ} \mathrm{C}, 16 \mathrm{~h}$ light and $8 \mathrm{~h}$ dark. The larval weights were recorded after five days, and each accession had 64 replications.

\subsection{Quantitative Proteomic Analysis}

\subsubsection{Protein Extraction and Digestion}

Leaves of IBS 3471 and ICPL 87 were harvested at both vegetative and flowering/podding stages and immediately placed on dry ice, for transport to the laboratory. The leaves were snap-frozen with liquid nitrogen and ground with a mortar and pestle. Protein extraction and digestion were as described by Wu et al. [37], using the trichloroacetic acid-acetone method.

2.6.2. Data Acquisition Using Nanoflow Liquid Chromatography-Electrospray Ionization-Tandem Mass Spectrometry (NanoLC ESI MS/MS)

Samples were tagged by tandem mass tag (TMT) reagent labelling of peptides (Thermo Fisher Scientific, USA), as per manufacturer's protocol. The labelled samples were prepared for MS analysis by reconstituting the high $\mathrm{pH}$ High-performance liquid chromatography (HPLC) fractions of each TMT set with $2 \%$ acetonitrile, $97.9 \%$ water and $0.1 \%$ formic acid (sample loading buffer). The samples were subjected to NanoLC-MS/MS system (Easy nLC 1000, Thermo Fisher Scientific, USA) and 1D Data-dependent acquisition (DDA) of peptides on Q-Exactive Quadrupole-Orbitrap (QE-Classic, Thermo Fisher Scientific, USA). The TMT labelled peptide samples were injected onto an in-house packed trap column (Halo C18, $160 \AA, 2.7 \mu \mathrm{m}, 100 \mu \mathrm{m} \times 3.5 \mathrm{~cm}$ ) and desalted with loading buffer. Peptides were eluted from the trap into an in-house packed analytical column with the linear gradients of mobile phase A $(99.9 \%$ water, $0.1 \%$ formic acid) and B ( $99.9 \%$ acetonitrile, $0.1 \%$ formic acid): mobile phase $\mathrm{B}(30 \%)$ over $110 \mathrm{~min}$ with a flow rate of $300 \mathrm{~nL} / \mathrm{min}$ across the gradient. The eluent from the trap was separated over the analytical column (Halo C18, $160 \AA, 2.7 \mu \mathrm{m}, 75 \mu \mathrm{m} \times 15 \mathrm{~cm}$ ). The column eluent was directed into the ionization source of the mass spectrometer. A $2.6 \mathrm{kV}$ electrospray voltage was applied via a liquid junction upstream of the column. Peptide precursors from 350 to $1850 \mathrm{~m} / \mathrm{z}$ were scanned at 70,000 resolution with an Automatic Gain Control (AGC) target value of $1 \times 10^{6}$ ions. The ten most intense ions from the preceding survey scan were fragmented by Higher-Energy Collisional Dissociation (HCD), using a normalized collision energy of $35 \%$ with an isolation width of $0.7 \mathrm{~m} / \mathrm{z}$. For MS/MS analysis, only precursors with a charge state of +2 to +4 were used. The MS method had a minimum signal required value of $2.5 \times 10^{4}$ for MS2 triggering, an AGC target value of 
$2 \times 10^{5}$ for MS2 and a maximum injection time of $250 \mathrm{~ms}$ for MS2. MS/MS scan resolution was set at 70,000 resolution, and the dynamic exclusion was $90 \mathrm{~s}$.

\subsubsection{Protein Identification and Quantification}

The raw data files from NanoLC ESI MS/MS were processed, using Proteome Discoverer version 2.1 (Thermo Fisher Scientific, Waltham, MA, USA). Subsequently, SequestHT and Mascot (Matrix Science, London, UK) search engines were used to process the data against $C$. cajan and $C$. scarabaeoides sequences downloaded from the UniProt database (47,669 sequences accessed on 19th July 2019 [38]). Conditions chosen for analysis were trypsin with two missed cleavage points, and the MS precursor mass tolerance was $\pm 20 \mathrm{ppm}$, with an MS/MS fragment mass tolerance of $0.02 \mathrm{Da}$. The dynamic modifications were oxidation of methionine, deamination of asparagine, glutamine and pyroglutamate, acetylation of protein $\mathrm{N}$-terminus, Met-loss+Acetyl (Sequest), and TMT6plex tag on lysine residues and the peptide $\mathrm{N}$-terminus. Static modification parameter was carbamido-methylation of cysteine. False discovery rate (FDR) was set at $<1 \%$, while the display filters were Protein, Peptide and PSM Master proteins only.

\subsection{Generation of Interspecific Hybrids}

ICPL 20338, a super-early maturing pigeonpea accession with the capability of escape mechanism for insects, was used as the female parent. To synchronise flowering, the male parent IBS 3471 was sown six weeks before the female parent (ICPL 20338). An artificial hybridisation procedure described by Singh and Oswalt [39] was used to generate the interspecific $F_{1}$ hybrids. The $F_{1}$ hybrids were self-pollinated to generate an $\mathrm{F}_{2}$ generation.

\subsection{Statistical Analysis}

All the collected data, including larvae weights, larval lifecycle (days), number of pupa and trichomes, and protein levels, were analysed using Minitab ${ }^{\circledR}$ Statistical Software (Version 18.1). Normal distribution and homogeneous variance were checked by using Normal probability plot of residuals. All the parameters comparing two means were analysed, using the independent $t$-test (the $p$-value of a Student's $t$-test $<0.05$ and $p<0.01$ ), while analysis of variance (one-way ANOVA) and post hoc mean comparisons with Tukey's HSD test at $p<0.05$ and $p<0.01$ was conducted for all parameters, comparing multiple means. Results were presented as the means $\pm \mathrm{SE}$.

\section{Results}

\subsection{IBS 3471 Leaves Inhibited Growth and Development of Helicoverpa Armigera Larvae}

On the preliminary plant choice bioassay done at the beginning of this study, using leaves, flowers and pods from the different $C$. scarabaeoides and C. cajan accessions, we observed that the larvae prefer to feed on cultivated pigeonpea and would feed on the wild pigeonpea if they have exhausted the cultivated pigeonpea (data not showed). Therefore, the intact leaf bioassay without choice was carried out, using the most preferred cultivated pigeonpea (ICPL 87) and the least preferred wild pigeonpea (IBS 3471).

H. armigera larval weight after eight days fed on C. scarabaeoides accession, IBS 3471, displayed significant $\left(t_{18}=8.42, p<0.001\right)$ inhibition of growth when compared to cultivated pigeonpea, $C$. cajan ICPL 87. The larvae fed on IBS 3471 leaves were $100.5 \mathrm{mg}$, while the larvae on ICPL 87 weighed 333.6 $\mathrm{mg}$ (Figure 1A). The development of $\mathrm{H}$. armigera larvae was also delayed, leading to a prolonged lifecycle when fed on the leaves of IBS 3471 compared to ICPL 87 (Figure 1B). Significant differences $\left(t_{18}=5.76, p<0.001\right)$ were observed between the larvae reared on ICPL 87 and IBS 3471 leaves. Larvae reared on ICPL 87 leaves took an average of 17 days to complete development and 28 days when reared on IBS 3471 leaves (Figure 1B). 


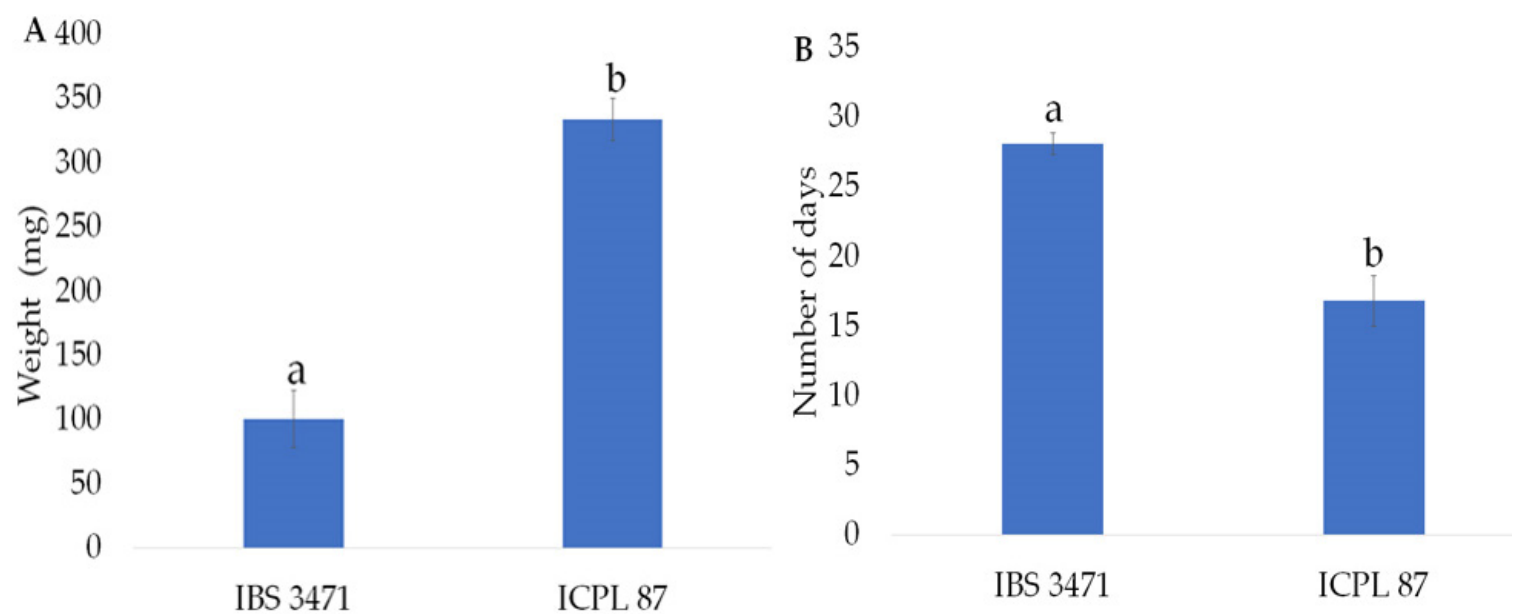

Figure 1. Average larval weight and larval lifecycle of $H$. armigera from detached intact leaf bioassay on C. scarabaeoides (IBS 3471) and C. cajan (ICPL 87). (A) Average larvae weight (mg) by day eight. (B) The average number of days from neonate larvae to pupa formation. Values labelled with different letters are significantly different at $p<0.05$ ( $t$-test). All data are means \pm standard errors $(n=10)$.

\subsection{Trichome Identification Revealed a Strong Antixenosis Defence Mechanism in IBS 3471}

In this study, the type (A, B, C and D), density, distribution, orientation and length of the trichomes differed considerably between IBS 3471 and ICPL 87 (Figure 2). Type A trichomes, which are glandular, produce exudates that attract and act as phagostimulant to $H$. armigera larvae [11], were only observed in ICPL 87. Type A trichomes were not observed on IBS 3471 leaves or pods. Leaves contained fewer type B trichomes compared to pods for both species (Figure 2). Moreover, the overall density of type B trichomes was lower in both species, compared to other trichome types. Both leaves and pods of IBS 3471 contained a high density of type $C$ and D trichomes. In contrast, the leaves of ICPL 87 contained very few type $C$ and $D$ trichomes (Figure 2).

\subsection{IBS 3471 Possesses Both Antibiosis and Antixenosis Insect-Resistance Mechanisms}

The results from intact-leaf bioassay and trichome characterisation indicate that IBS 3471 significantly $\left(t_{171}=7.75, p<0.001\right)$ inhibited the growth and development of $H$. armigera by antixenosis mechanism. To understand whether the inhibition was by antixenosis or whether antibiosis also played a role, $H$. armigera larvae were reared on an artificial diet supplemented with lyophilised leaf powder from the two genotypes. H. armigera larval weights were significantly $\left(t_{124}=6.98, p<0.001\right)$ lower when reared on an artificial diet supplemented with lyophilised leaf powder from 11 different C. scarabaeoides accessions, compared with larvae reared on the artificial diet with lyophilised leaf powder of susceptible cultivated pigeonpea variety, ICPL 87, (Supplementary Figure S1). Larvae fed on an artificial diet supplemented with ICPL 87 lyophilised leaf powder had the highest average weight of $304.6 \mathrm{mg}$, compared to those fed on an artificial diet supplemented with lyophilised leaf powder of IBS 3471, which had the least average weight of $182.3 \mathrm{mg}$ by day five (Figure 3A). Delayed development was also observed in larvae fed on an artificial diet supplemented with leaf powder of IBS 3471 compared to ICPL 87 . Approximately $42 \%$ of larvae reared on an artificial diet supplemented with lyophilised leaf powder of IBS 3471 had pupated within 11 days, whereas $88 \%$ of the larvae fed on an artificial diet with leaf powder of ICPL 87 had already pupated by day 11 (Figure 3B). 
A

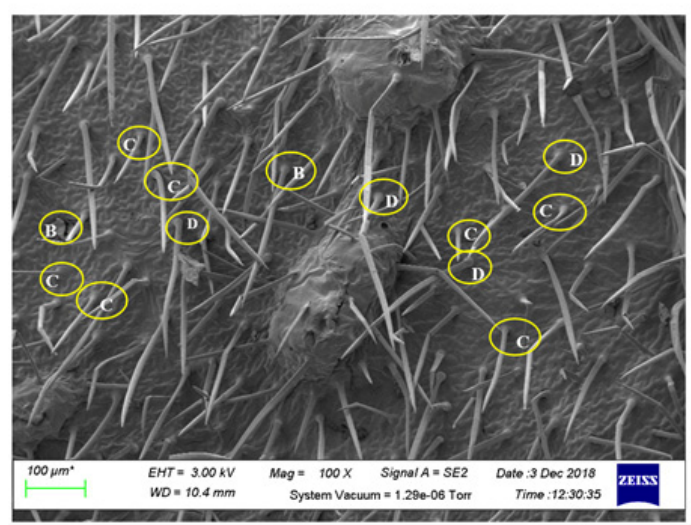

B

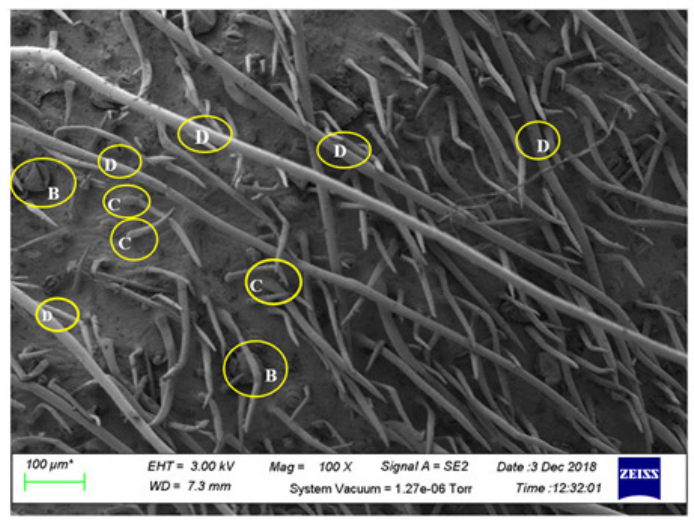

$\mathrm{C}$

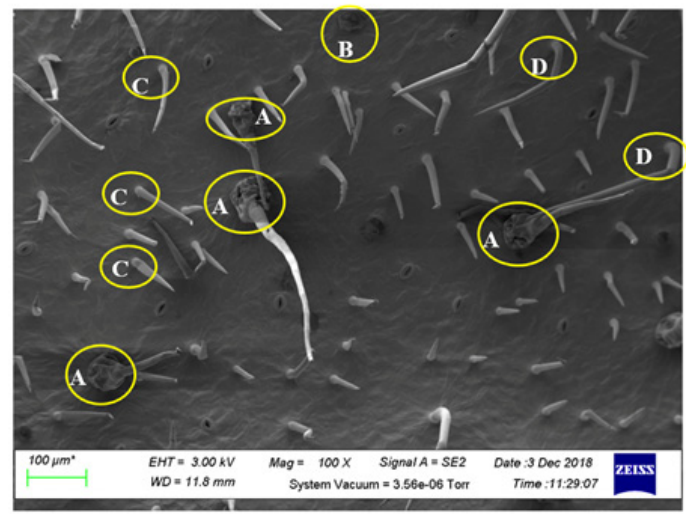

D

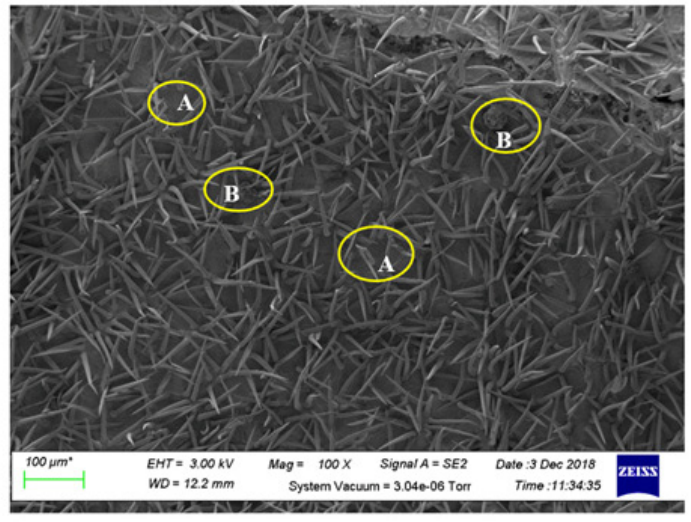

E

$$
\begin{aligned}
& \text { 군 } 36 \\
& \text { 芚 } 32 \\
& \text { เกี } 28 \\
& \text { ㄴ. } 24 \\
& \text { ह } 20 \\
& \text { 吕 } 16 \\
& \text { จ } 12
\end{aligned}
$$

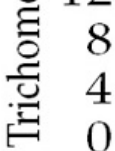

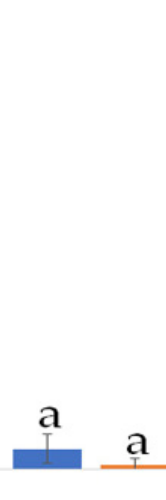

B

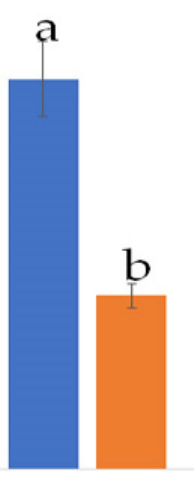

$\mathrm{C}$

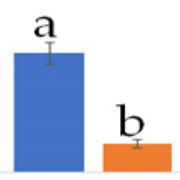

$\mathrm{D}$

\section{IBS 3471 Leaf $\quad$ ICPL 87 Leaf}

Figure 2. Scanning electron micrographs of different trichome types for IBS 3471 and ICPL 87 at 100X magnification. (A) IBS 3471 leaf, (B) IBS 3471 pod, (C) ICPL 87 leaf, (D) ICPL 87 pod and (E) Leaf trichome number per $0.5 \mathrm{~mm}^{2}$ for IBS 3471 and ICPL 87 . The different trichome types are identified with letters in yellow circles. All scale bars are $100 \mu \mathrm{m}$. Values labelled with different letters are significantly different at $p<0.05$ ( $t$-test). All data are means \pm standard errors $(n=3)$. 


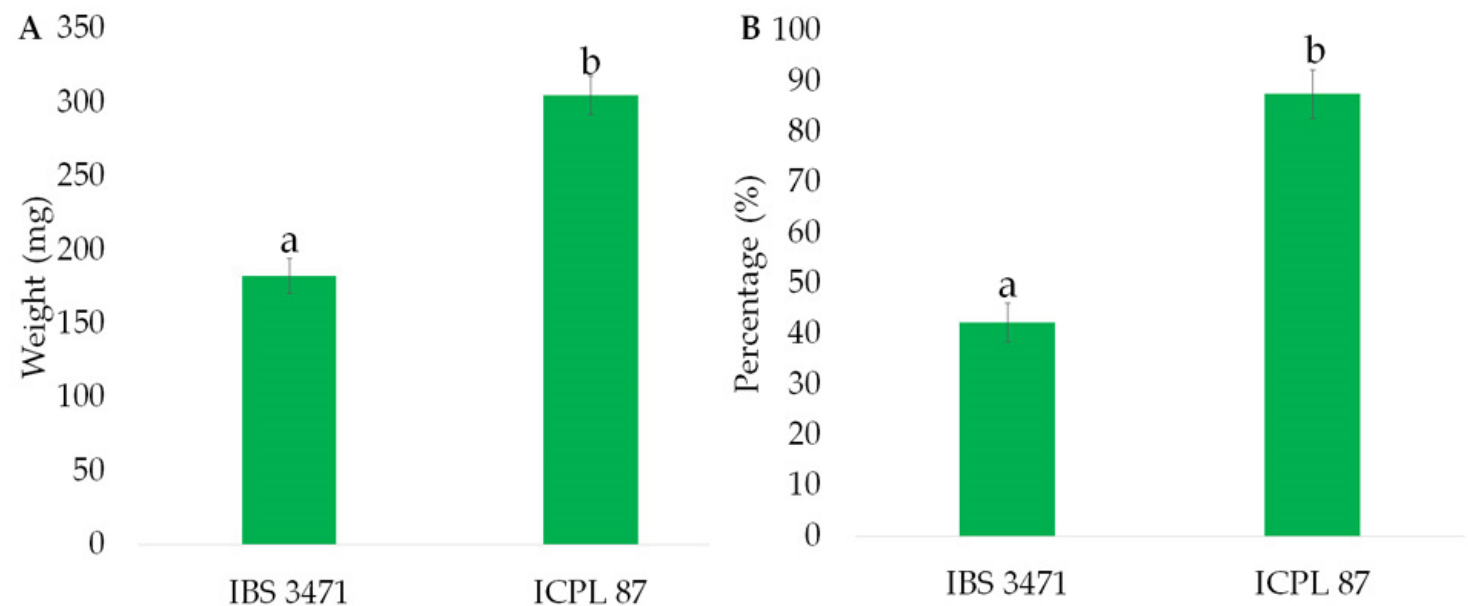

Figure 3. Average larval weight and percentage of pupation when $H$. armigera larvae were fed on C. scarabaeoides (IBS 3471) and C. cajan (ICPL 87) based artificial diets. (A) Average larval weight (mg) by day five. (B) Percentage of pupated $H$. armigera larvae by day 11 . Values labelled with different letters are significantly different at $p<0.01$ ( $t$-test). All data are means \pm standard errors $(n=64)$.

\subsection{Insect-Resistance Factors in Pigeonpea Were Heat-Labile}

To further investigate the component/s contributing to insect-resistance in pigeonpea, we heated the artificial diet supplemented with lyophilised leaf powder of $C$. scarabaeoides and C. cajan and assessed the growth of $H$. armigera for differences compared to non-heated media. A significant difference $\left(F_{5,377}\right.$ $=43.89, p<0.001)$ in the weight of $H$. armigera larvae fed on the heated and non-heated artificial diets was observed. Average larval weight of $H$. armigera (day five) reared on heat-treated leaf powder was 244.8 and $384.27 \mathrm{mg}$ for IBS 3471 and plain artificial diet (PAD), respectively (Figure 4A). Meanwhile, the weights of larvae that were fed on a non-heat-treated artificial diet with leaf powder had less weight, with $182.3 \mathrm{mg}$ for IBS 3471 and $354.4 \mathrm{mg}$ for PAD on day five (Figure 4A). Larvae fed on the artificial diet with ICPL 87 leaf powder for both heat and non-heat-treated diet had a higher weight when compared with larvae fed on the artificial diet with IBS 3471 leaf powder. Statistically, no significant $(p<0.01)$ differences were observed on heated or non-heated PAD, confirming that the heating process does not destroy any ingredient in the diet, contributing to the experimental differences (Figure 4A).
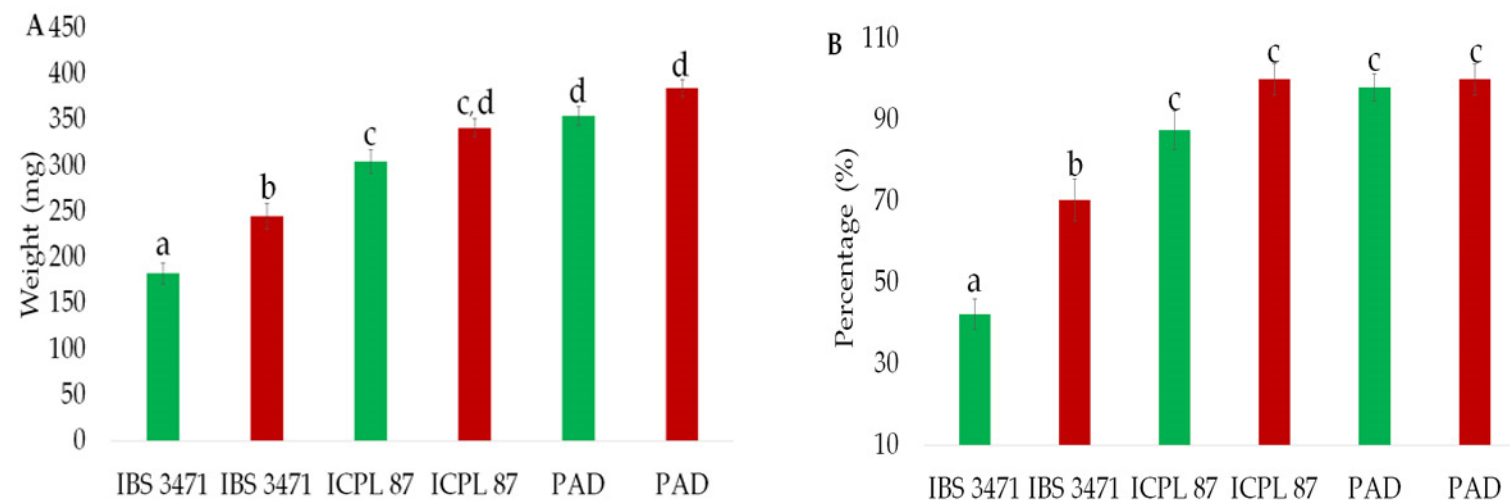

Figure 4. Effect of heated and non-heated artificial diet with lyophilised leaf powder on weight (mg) and pupation (\%) of $H$. armigera larvae. (A) Average larval weight of $H$. armigera fed on an artificial diet supplemented with lyophilised leaf powder of IBS 3471 and ICPL 87 on a non-heated diet (green bars) and heated diet (red bars). (B) Percentage of pupated H. armigera larvae fed on a non-heated diet (green bars) and heated diet (red bars) artificial diet with lyophilised leaf powder by day 11. Values labelled with different letters are significantly different at $p<0.01$ (Tukey's HSD test). All data are means \pm standard errors $(n=64)$. PAD: plain artificial diet. 
There was less profound delayed development on the larvae fed on both heated and non-heated artificial diet supplemented with lyophilised leaf powder of ICPL 87 (Figure 4B). However, no delay in the development for larvae reared on both heated and non-heated PAD was observed (Figure 4B). By day $11,100 \%$ of the larvae fed on a heat-treated artificial diet supplemented with lyophilised leaf powder of ICPL 87 had pupated, consistent with those fed on PAD. In contrast, $88 \%$ of the larvae fed on a non-heated artificial diet with lyophilised powder of ICPL 87 had pupated (Figure 4B). Seventy per cent of larvae fed on a heat-treated artificial diet supplemented with lyophilised leaf powder of IBS 3471 pupated by day 11, whereas only $42 \%$ pupation was observed on the larvae fed on a non-heated artificial diet supplemented with lyophilised leaf powder of IBS 3471 (Figure 4B). These results indicated that the effects of insect-resistance component/s in leaves of pigeonpea were significantly $\left(F_{5,378}=33.0, p<0.001\right)$ reduced by heat.

\subsection{Proteomic Analysis Revealed High Presence of Two Potential Defence Proteins for Helicoverpa Armigera} Resistance in IBS 3471

To investigate heat-labile insect-resistance components in pigeonpea, we performed a proteomic analysis on IBS 3471 and ICPL 87 genotypes. There were significant differences $(t(2)=6.92, p=0.02$, $t(4)=2.81, p=0.048$ ) in the levels of cysteine proteinase inhibitors (Figure 5A,B, respectively, and Supplementary Table S3). Leaves at the vegetative stage of IBS 3471 contained a 5.1-times-higher level of cysteine protease inhibitor than leaves of ICPL 87 at the same stage (Figure 5A,B). There was a two-fold reduction in cysteine proteinase inhibitor detected during the flowering and podding stage in IBS 3471 and a minimal increase in ICPL 87 (Figure 5B). There were significant differences $(t(2)=14.41$, $p=0.005, t(4)=9.09, p=0.001$ ) in the levels of lectin-domain containing receptor kinase (Figure $5 \mathrm{C}, \mathrm{D}$, respectively, and Supplementary Table S3). The lectin-domain containing receptor kinase was 2.5 times higher in the leaf of IBS 3471 than in leaf of ICPL 87, at the vegetative stage (Figure 5C). For the flowering and podding stage, IBS 3471 accumulated two times more lectin-domain containing receptor kinase than ICPL 87 (Figure 5D).

\subsection{Insect-Resistance Components in IBS 3471 Are Transferrable to Cultivated Pigeonpea}

Generation of interspecific hybrids is one possible strategy of improving the resistance of cultivated pigeonpea against pest damage, especially pod borers. In this study, $F_{1}$ and $F_{2}$ interspecific hybrids were generated and feeding bioassays conducted. The insect-resistance levels in $F_{1}$ and $F_{2}$ hybrids were comparable to their paternal parent IBS 3471 (Figure 6A). The larvae fed on the maternal parent ICPL 20338 diet had more weight $\left(161.1 \mathrm{mg}\right.$ ) than larvae fed on the $F_{1}$ hybrid $(58.5 \mathrm{mg}$ ) and IBS 3471 ( $54.3 \mathrm{mg}$ ) by day eight (Figure 6A). Larvae fed on an artificial diet supplemented with lyophilised leaf powder of the paternal parent IBS 3471 were $167.8 \mathrm{mg}$, those on the hybrid $\mathrm{F}_{2}$ generation diet were $182.4 \mathrm{mg}$ and those on the maternal parent ICPL 20338 were $323.6 \mathrm{mg}$ by day five (Figure 6B). No significant differences $\left(F_{2,93}=24.46, p<0.001\right)$ were observed in larval weight between IBS 3471 and the $\mathrm{F}_{2}$ hybrid (Figure $6 \mathrm{~B}$ ). 

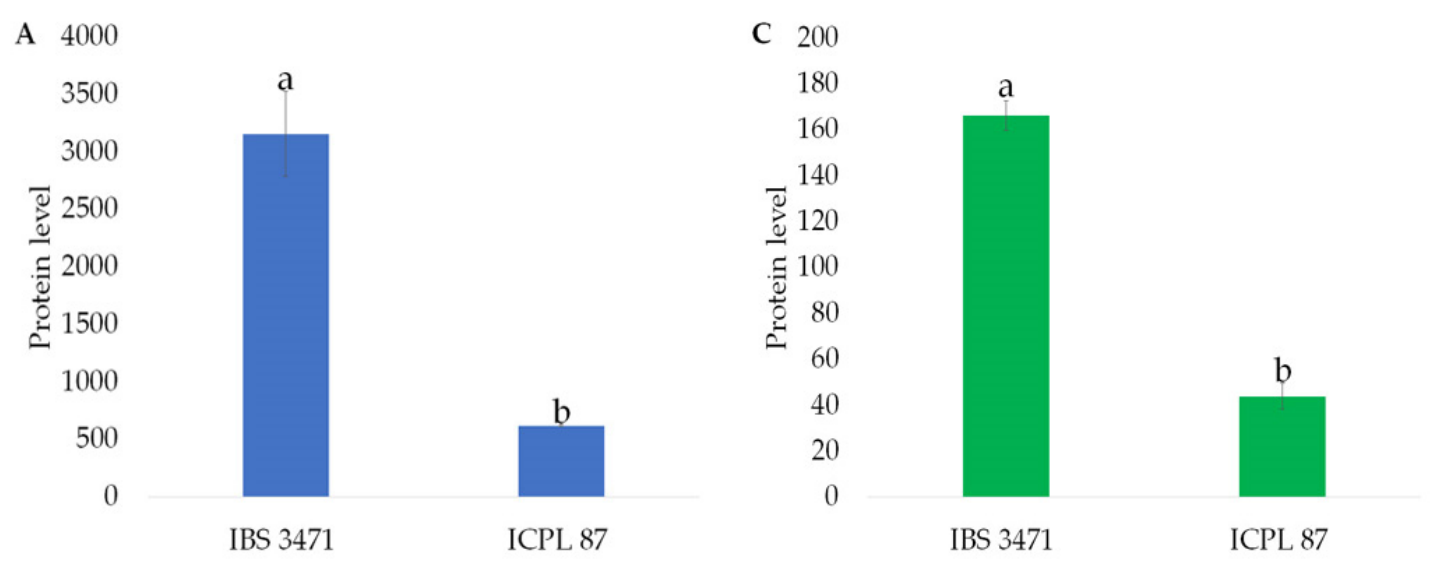

B
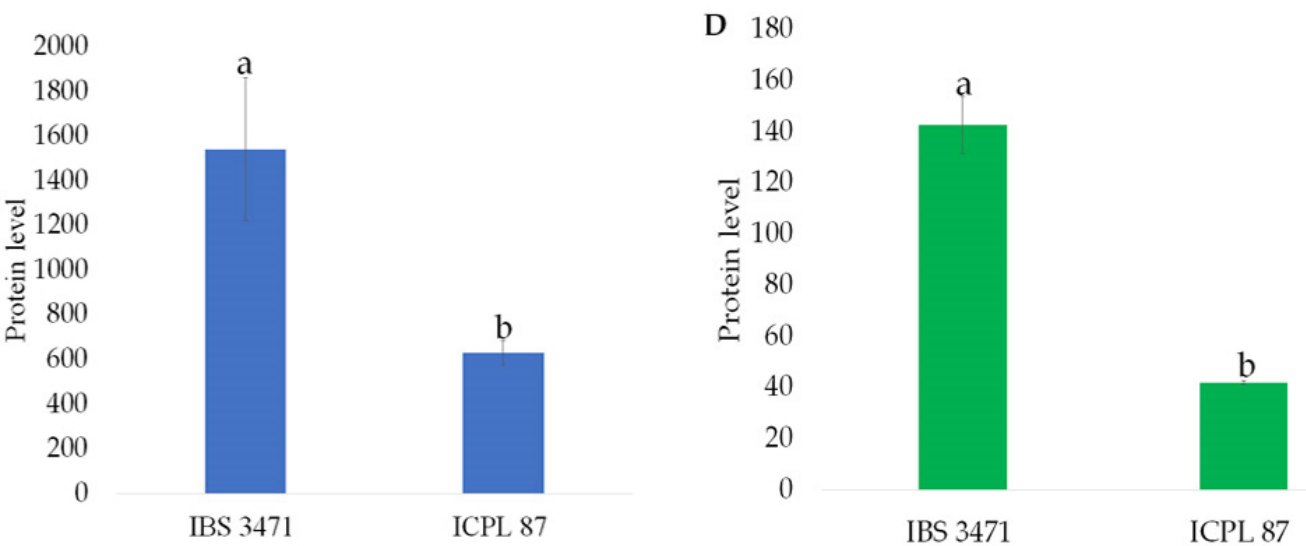

Figure 5. Protein levels in C. scarabaeoides (IBS 3471) and C. cajan (ICPL 87) leaves. (A) Cysteine proteinase inhibitor at the vegetative stage. (B) Cysteine proteinase inhibitor at the flowering and podding stage. (C) Lectin-domain containing receptor kinase at vegetative stage. (D) Lectin-domain containing receptor kinase at the flowering and podding stage. Values labelled with different letters are significantly different at $p<0.05(\mathbf{A}, \mathbf{B})$ and $p<0.01$ (C,D) (Tukey's HSD test). All data are means \pm standard errors ( $n=2$ for vegetative stage and $n=3$ for flowering and podding stage).

Analysis of the trichomes present on the leaves and pods indicated that the $\mathrm{F}_{2}$ hybrid contained similar trichome types, density and length to its highly insect-resistant paternal parent, IBS 3471 (Figure 6C-I). These results confirm that insect-resistance components from IBS 3471 were transferred to the progeny. 


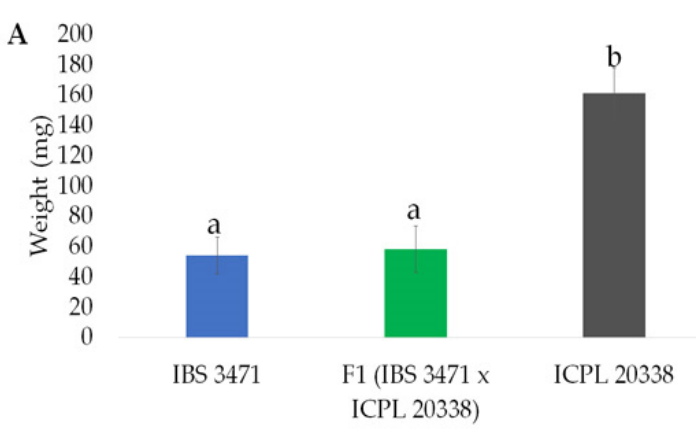

B 400
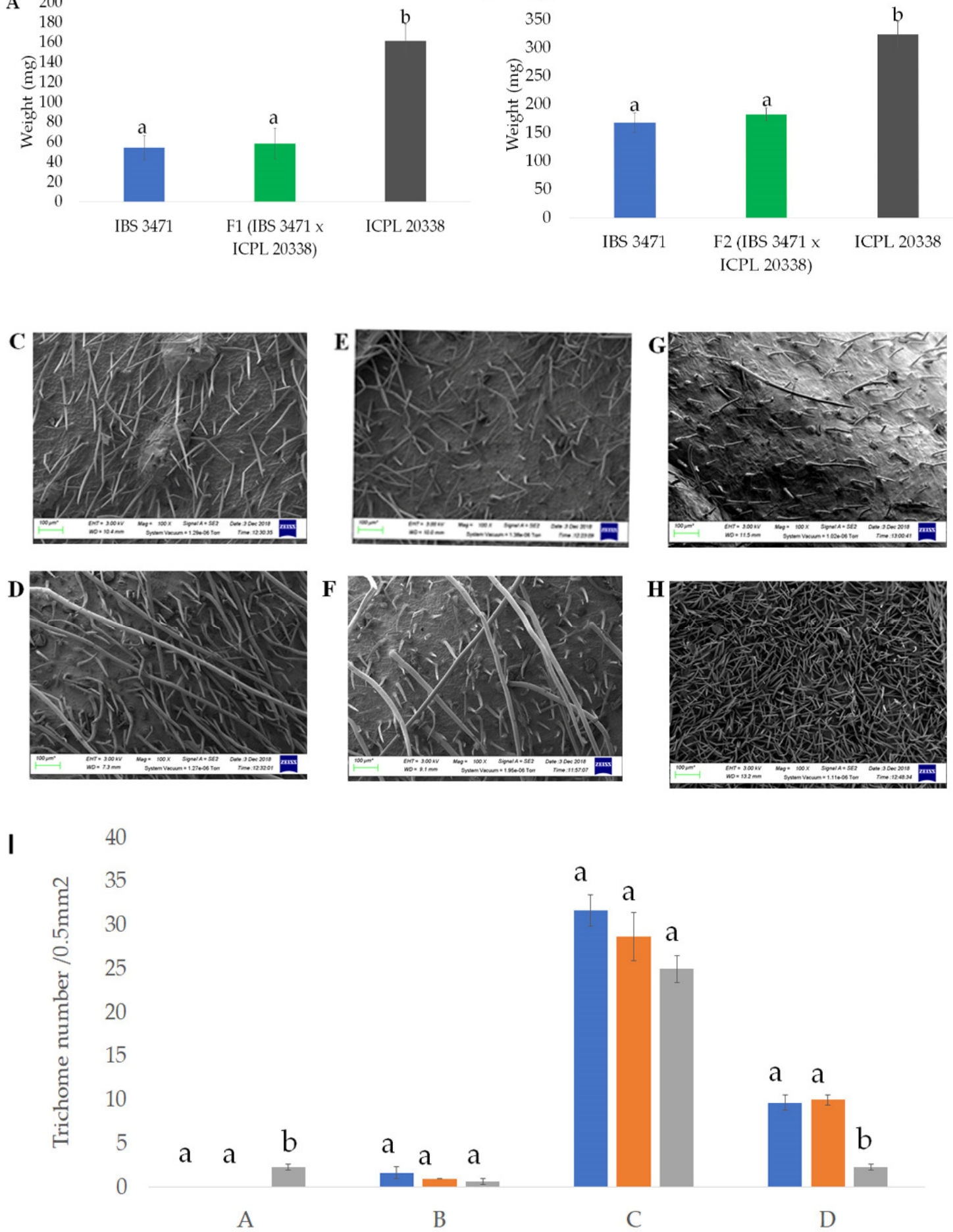

A

C

D

IBS 347 Interspecific hybrid $\quad$ ICPL 20338

Figure 6. Insect-feeding bioassays, using intact detached leaves and an artificial diet supplemented with lyophilised leaf powder and scanning electron micrographs of trichomes of interspecific hybrid and its parents. (A) Average larval weight $(\mathrm{mg})$ of neonate $H$. armigera larvae fed on $\mathrm{F}_{1}$ interspecific hybrid and its parents intact detached leaves by day eight. (B) Average larval weight (mg) of neonate $H$. armigera larvae fed on an artificial diet supplemented with lyophilised leaf powder of $\mathrm{F}_{2}$ interspecific hybrid and its parents by day five. (C-H) Scanning electron micrographs of trichomes on the $\mathrm{F}_{2}$ interspecific hybrid and its parents at 100X magnification (scale bars $=100 \mu \mathrm{m}$ ), (C) IBS 3471 leaf, (D) IBS 3471 pod, (E) $F_{2}$ interspecific hybrid leaf, (F) $F_{2}$ interspecific hybrid pod, (G) ICPL 20338 leaf, (H) 
ICPL 20338 pod and (I) Leaf trichome number per $0.5 \mathrm{~mm}^{2}$ for IBS 3471, $\mathrm{F}_{2}$ interspecific hybrid and ICPL 20338. Values labelled with different letters are significantly different at $p<0.05$ (A) and $p<0.01$ (B) (Tukey's HSD test). All data are means \pm standard errors $\left(n=10\right.$ for $\mathrm{F}_{1}$ and $n=32$ for $\mathrm{F}_{2}$ and $n=3$ for Trichome count).

\section{Discussion}

Crop improvement programs depend heavily on the availability of relevant germplasm. To utilise the resources available in a gene bank, the genetic diversity of the germplasm collection needs to be characterised [40]. Helicoverpa armigera is a major threat affecting pigeonpea production worldwide [5]. Wild pigeonpea has a high resistance to $H$. armigera and therefore has potential as a donor source for this trait to be incorporated into cultivated pigeonpea, provided there is no yield drag associated with the transfer [5]. In this study, we investigated the insect-resistance components in one of the closest relatives to cultivated pigeonpea, namely $C$. scarabaeoides, and explored the possibility of transferring one or more of the insect-resistant mechanisms to cultivated pigeonpea C. cajan.

Out of the 11 C. scarabaeoides accessions obtained from the Australian Grains Genebank (Supplementary Table S1 and Figure S1), IBS 3471 accession demonstrated the highest level of resistance to $H$. armigera. In addition, IBS 3471 accession had better nutritional profile (Supplementary Table S2), making it an ideal candidate for use in an interspecific hybridisation program. This study proposes that IBS 3471 possesses both antixenosis (non-host preference) and antibiosis (harmful effect on insect biology) insect-resistance mechanisms. The antixenosis resistance mechanism present in IBS 3471 seemed to be related to the presence of dense, long and various types of trichomes on the leaves and pods (Figure 2). Trichomes provide insect-resistance by producing sticky exudates which hinder the insect, producing toxic chemicals which poison the insect through contact/ingestion/inhalation and acting as physical barriers preventing insect contact with the plant [41]. Trichome types, orientation, density and length influence insect damage in several crops [7]. Pigeonpea has five distinct types of trichomes (type A, B, C, D and E) that are identified by light or scanning electron microscopy [8]. Type A trichomes are glandular and secrete exudates, which act as attractants and phagostimulants toward H. armigera larvae [11,42]. Type B trichomes are globular and comprise an oily substance, which gives pigeonpea the characteristic fragrant smell [43]. The contents of type B trichomes are released upon the breakdown of the cell wall, caused either by chewing insects (H. armigera) or by abiotic factors (e.g., high temperatures or low air humidity). Type $\mathrm{C}$ and $\mathrm{D}$ are non-glandular trichomes. Type D trichomes are longer than type C [11,42]. Type E trichomes are multilobed, glandular and small, and therefore can only be identified by electron microscopy [11]. Results from this study showed that the types, density, distribution, orientation and length of the trichomes in leaf and pod varied considerably between IBS 3471 and ICPL 87, correlating with the different capacities of these genotypes to resist insect-feeding bioassay (Figure 2). Type A trichomes that act as H. armigera larvae attractants and phagostimulants were only present in the cultivated pigeonpea variety, ICPL 87 (Figure 2C,D). Conversely, the non-glandular trichomes (type $\mathrm{C}$ and $\mathrm{D}$ ), which may act as a physical barrier to feeding by $H$. armigera larvae $[11,42,44]$, were present at much higher densities on the leaves and pods of IBS 3471, compared to ICPL 87 (Figure 2). Bioassays using intact detached leaves demonstrated that $H$. armigera larvae reared on C. scarabaeoides leaves, which have dense and long trichomes, had significantly lower weights compared to larvae reared on ICPL 87 . This result coincides with the findings reported by Green et al. [42] and Sujana et al. [44].

To enable the improvement of insect-resistance in crops through breeding programs, donor parents should possess as many insect-resistant mechanisms as possible. In this study, we found that IBS 3471 possesses antixenosis, as well as antibiosis, resistance mechanisms. H. armigera larvae reared on an artificial diet supplemented with lyophilised IBS 3471 leaf powder had less weight and a prolonged developmental period, as compared to the larval reared on an artificial diet supplemented with lyophilised leaf powder of ICPL 87 (Figures 3 and 4). The differential of larval weight suggests 
the presence of more effective antibiosis defence systems in C. scarabaeoides, potentially involving proteinase inhibitors, phenolic or flavonoid compounds [45,46]. Delayed insect development is a good indicator of an antibiosis defence mechanism against pests [44]. Practically, delays in the pest growth cycle provide an opportunity to control $\mathrm{H}$. armigera larvae through application of insecticides at the early stage of larval growth, before it reaches the destructive stage, and also insecticides are more effective on small larvae (below fifth instar) [36].

Plant protease inhibitors (PPIs) play crucial roles in plant defence against insects, pathogenic nematodes and fungi. They are also among the most abundant proteins in plants $[3,47,48]$. Several in vitro and in vivo studies showed that PPIs are toxic to larval gut proteases, causing digestion defects and disruption of amino acid absorption. Besides, PPIs result in retarded growth and development of the larvae, consequently affecting the fecundity and productivity of the moth [13]. Similarly, C. scarabaeoides accession IBS 3471 contained the largest quantities of cysteine proteinase inhibitors and lectin-domain containing receptor kinases (Figure 5), resulting in the most significant inhibition to H. armigera larval growth (Figures 1,3 and 4; Supplementary Table S3). Swathi et al. [49] had a similar observation, where pigeonpea protease inhibitors affected H. armigera gut proteinases. In addition, Prasad et al. [50] reported reduced activity of proteinases in the midgut of Manduca sexta larvae by proteinase inhibitors from pigeonpea and black gram.

Plant domestication has produced varieties containing low genetic variation. This is particularly true for self-pollinated crops such as pigeonpea. This is a result of using breeding methods which exclusively involved selection and mating of genetically related individuals, to generate elite varieties. This may have resulted in random loss of alleles, leading to genetic erosion, causing several genetic bottlenecks [51]. This is changing, as modern breeding programs are broadening and improving cultivated gene pools by using crop wild relatives [4]. Therefore, the use of wide hybridisation to introgress useful genes, such as insect-resistance genes, is one mechanism of broadening the genetic base of cultivated pigeonpea to combat pod borers.

The interspecific hybrid and the $\mathrm{F}_{2}$ population derived from it inherited the insect-resistance mechanisms that inhibit the growth and development of the H. armigera larvae from the paternal parent C. scarabaeoides IBS 3471 (Figure 6). Similar results were reported by Dodia et al. [52], in which they observed the adverse effects of $C$. scarabaeoides and their $F_{1}$ derivates on $H$. armigera larvae. Together with previous studies, this research confirms that wild pigeonpea, C. scarabaeoides, can be used as a donor for transferring pod-borer-resistance into cultivars through wide hybridisation, as suggested and observed by [3,52-54].

\section{Conclusions}

The global population is growing at an unprecedented rate, and the demand for plant-based proteins is set to increase. Pigeonpea is an important pulse crop for the semi-arid tropics. It is one of the premium legumes and a major source of protein to over $20 \%$ of the world's population based largely on the Indian subcontinent. Despite its importance, pigeonpea productivity is substantially hindered by insect pressure such as Helicoverpa armigera (pod borer). This study has identified IBS 3471, a C. scarabaeoides accession, as a potential candidate for improvement of insect-resistance in pigeonpea. Further experiments are in progress to gain a better understanding of how the two-potential insect-resistant proteins, namely cysteine proteinase inhibitor and lectin domain-containing receptor kinase in IBS 3471, are involved in H. armigera resistance. This study has shown that the resistance traits from wild pigeonpea are transferable and stable at $\mathrm{F}_{2}$ population; therefore, this can be used to improve insect resistance in a largescale breeding programs involving different cultivated pigeonpea with multiple resistance to $H$. armigera.

Supplementary Materials: The following are available online at http://www.mdpi.com/2073-4395/10/4/517/s1. Table S1. Preliminary screening for insect-resistance, using non-heat-treated artificial diet supplemented with lyophilised leaf powder from 11 accessions of C. scarabaeoides and C. cajan received from Australian Grains Genebank. Figure S1. Average larval weight of H. armigera fed on different accessions of C. scarabaeoides and 
C. cajan, using non-heated (green bars) and heated (red bars) artificial diet supplemented with lyophilised leaf powder. Table S2. Mineral and protein composition of raw mature pigeonpea seeds. Table S3. Summary of protein abundance for cysteine proteinase inhibitor and lectin-domain containing receptor kinase A4.2 in Cajanus cajan (ICPL 87) and Cajanus scarabaeoides (IBS 3471) leaves.

Author Contributions: Conceptualization, methodology, validation and visualization, A.N.-D., T.M.L.H., B.W., T.J.V.H. and S.G.M.; investigation and resources, A.N.-D. and T.M.L.H.; writing-original initial draft preparation, A.N.-D.; writing-review and editing, A.N.-D., T.M.L.H., B.W., T.J.V.H. and S.G.M.; Supervision, T.M.L.H., B.W., T.J.V.H. and S.G.M.; funding and project administration, T.M.L.H. and S.G.M. All authors have read and agreed to the published version of the manuscript.

Funding: This project was funded by Advance Queensland Research Fellowship package grant numbers AQRF14816-17RD2, AQRF04016-17RD2 and AQRF14716-17RD2. A.N.-D. is a QUT-HDR Sponsorship and Associated Grain scholarship recipient.

Acknowledgments: The authors acknowledge QUT-CARF and Julia Bally (QUT-CAB) for the technical support, the Australian Grains Genebank (AGG), (Horsham, Victoria, Australia) and the International Crops Research Institute for the Semi-Arid Tropics (ICRISAT) (Patancheru, Hyderabad, India) for providing the seeds used in the study. This research has been facilitated by access to Macquarie University's Australian Proteome Analysis Facility, which is funded by an initiative of the Australian Government, as part of the National Collaborative Research Infrastructure Strategy.

Conflicts of Interest: The authors declare no conflict of interest.

\section{References}

1. Choudhary, A.K.; Raje, R.S.; Datta, S.; Sultana, R.; Ontagodi, T. Conventional and Molecular Approaches towards Genetic Improvement in Pigeonpea for Insects Resistance. Am. J. Plant Sci. 2013, 4, 372-385. [CrossRef]

2. FAOSTAT. Available online: http://www.fao.org/faostat/en/\#data/QC/visualize (accessed on 23 September 2019).

3. Saxena, K.B.; Kumar, R.V.; Rao, P.V. Pigeonpea Nutrition and Its Improvement. J. Crop Prod. 2002, 5, $227-260$. [CrossRef]

4. Bohra, A.; Mallikarjuna, N.; Saxena, K.; Upadhyaya, H.; Vales, I.; Varshney, R. Harnessing the potential of crop wild relatives through genomics tools for pigeonpea improvement. J. Plant Biol. 2010, 37, 83-98.

5. Sharma, H. Crop protection compendium: Helicoverpa armigera. In Electron. Compend. Crop Prot; 2001; CAB International: Wallingford, UK; ISSN 1478-7040. Available online: www.cabi.org/cpc (accessed on 2 April 2020).

6. Kumari, D.A.; Reddy, D.J.; Sharma, H.C. Antixenosis mechanism of resistance in pigeonpea to the pod borer, Helicoverpa armigera. J. Appl. Entomol. 2006, 130, 10-14. [CrossRef]

7. Aruna, R.; Rao, D.M.; Reddy, L.; Upadhyaya, H.D.; Sharma, H.C. Inheritance of trichomes and resistance to pod borer (Helicoverpa armigera) and their association in interspecific crosses between cultivated pigeonpea (Cajanus cajan) and its wild relative C. scarabaeoides. Euphytica 2005, 145, 247-257. [CrossRef]

8. Romeis, J.; Shanower, T.; Peter, A. Trichomes on pigeonpea [Cajanus cajan (L.) Millsp.] and two wild Cajanus spp. Crop Sci. 1999, 39, 564-569. [CrossRef]

9. Simmons, A.T.; Gurr, G.M. Trichome-based host plant resistance of Lycopersicon species and the biocontrol agent Mallada signata: Are they compatible? Entomol. Exp. Appl. 2004, 113, 95-101. [CrossRef]

10. Kärkkäinen, K.; Ågren, J.J.H. Genetic basis of trichome production in Arabidopsis lyrata. Hereditas 2002, 136, 219-226. [CrossRef]

11. Sharma, H.C.; Sujana, G.; Manohar, R.D. Morphological and chemical components of resistance to pod borer, Helicoverpa armigera in wild relatives of pigeonpea. Arthropod Plant Interact. 2009, 3, 151-161. [CrossRef]

12. Sharma, H.C.; Pampapathy, G.; Dhillon, M.K.; Ridsdill-Smith, J.T. Detached leaf assay to screen for host plant resistance to Helicoverpa armigera. J. Econ. Entomol. 2005, 98, 568-576. [CrossRef]

13. Shamsi, T.N.; Parveen, R.; Ahamad, S.; Fatima, S. Structural and biophysical characterization of Cajanus cajan protease inhibitor. J. Nat. Sci. Biol. Med. 2017, 8, 186. [CrossRef]

14. Chrispeels, M.J.; Raikhel, N.V. Lectins, lectin genes, and their role in plant defense. Plant Cell 1991, $3,1$. [CrossRef]

15. Ryan, C.A. Protease inhibitors in plants: Genes for improving defenses against insects and pathogens. Annu. Rev. Phytopathol. 1990, 28, 425-449. [CrossRef] 
16. Singh, P.; Zimmerli, L. Lectin receptor kinases in plant innate immunity. Front. Plant Sci. 2013, 4, 124. [CrossRef] [PubMed]

17. Habib, H.; Fazili, K.M. Plant protease inhibitors: A defense strategy in plants. Biotechnol. Mol. Biol. Rev. 2007, 2, 68-85.

18. Quilis, J.; Meynard, D.; Vila, L.; Avilés, F.X.; Guiderdoni, E.; San Segundo, B. A potato carboxypeptidase inhibitor gene provides pathogen resistance in transgenic rice. Plant Biotechnol. J. 2007, 5, 537-553. [CrossRef] [PubMed]

19. Koiwa, H.; Bressan, R.A.; Hasegawa, P.M. Regulation of protease inhibitors and plant defense. Trends Plant Sci. 1997, 2, 379-384. [CrossRef]

20. Tamhane, V.A.; Chougule, N.P.; Giri, A.P.; Dixit, A.R.; Sainani, M.N.; Gupta, V.S. In vivo and in vitro effect of Capsicum annum proteinase inhibitors on Helicoverpa armigera gut proteinases. Biochim. Biophys. Acta Gen. Subj. 2005, 1722, 156-167. [CrossRef]

21. Lawrence, P.K.; Koundal, K.R. Plant protease inhibitors in control of phytophagous insects. Electron. J. Biotechnol. 2002, 5, 5-6. [CrossRef]

22. Spit, J.; Holtof, M.; Badisco, L.; Vergauwen, L.; Vogel, E.; Knapen, D.; Vanden Broeck, J. Transcriptional analysis of the adaptive digestive system of the migratory locust in response to plant defensive protease inhibitors. Sci. Rep. 2016, 6, 32460. [CrossRef]

23. Srinivasan, A.; Chougule, N.P.; Giri, A.P.; Gatehouse, J.A.; Gupta, V.S. Pod borer (Helicoverpa armigera Hübn.) does not show specific adaptations in gut proteinases to dietary Cicer arietinum Kunitz proteinase inhibitor. J. Insect Physiol. 2005, 51, 1268-1276. [CrossRef] [PubMed]

24. Jongsma, M.A.; Bolter, C. The adaptation of insects to plant protease inhibitors. J. Insect Physiol. 1997, 43, 885-895. [CrossRef]

25. Haq, S.K.; Atif, S.M.; Khan, R.H. Protein proteinase inhibitor genes in combat against insects, pests, and pathogens: Natural and engineered Phyto-protection. Arch. Biochem. Biophys. J. 2004, 431, 145-159. [CrossRef] [PubMed]

26. Richardson, M. Seed Storage Proteins: The Enzyme Inhibitors; Dey, P.M., Harborne, J.B., Eds.; Academic Press: New York, NY, USA, 1991.

27. Al Atalah, B.; Smagghe, G.; van Damme, E.J.M. Orysata, a jacalin-related lectin from rice, could protect plants against biting-chewing and piercing-sucking insects. Plant Sci. 2014, 221, 21-28. [CrossRef]

28. Bandyopadhyay, S.; Roy, A.; Das, S. Binding of garlic (Allium sativum) leaf lectin to the gut receptors of homopteran pests is correlated to its insecticidal activity. Plant Sci. 2001, 161, 1025-1033. [CrossRef]

29. Dutta, I.; Saha, P.; Majumder, P.; Sarkar, A.; Chakraborti, D.; Banerjee, S.; Das, S. The efficacy of a novel insecticidal protein, Allium sativum leaf lectin (ASAL), against homopteran insects monitored in transgenic tobacco. Plant Biotechnol. J. 2005, 3, 601-611. [CrossRef] [PubMed]

30. Dutta, I.; Majumder, P.; Saha, P.; Ray, K.; Das, S. Constitutive and phloem specific expression of Allium sativum leaf agglutinin (ASAL) to engineer aphid (Lipaphis erysimi) resistance in transgenic indian mustard (Brassica juncea). Plant Sci. 2005, 169, 996-1007. [CrossRef]

31. Bharathi, Y.; Vijaya Kumar, S.; Pasalu, I.C.; Balachandran, S.M.; Reddy, V.D.; Rao, K.V. Pyramided rice lines harbouring Allium sativum (ASAL) and Galanthus nivalis (GNA) lectin genes impart enhanced resistance against major sap-sucking pests. J. Biotechnol. 2011, 152, 63-71. [CrossRef]

32. Gupta, P.; Anuradha, S.; Gaurav, S.; Neeraj, W. Bio-insecticidal potential of amylase inhibitors. J. Pharm. Res. 2013, 1, 449-458.

33. Ishimoto, M.; Sato, T.; Chrispeels, M.J.; Kitamura, K. Bruchid resistance of transgenic azuki bean expressing seed a-amylase inhibitor of common bean. Entomol. Exp. Appl. 1996, 79, 309-315. [CrossRef]

34. Schroeder, H.E.; Gollash, S.; Moore, A.; Tabe, L.M.; Craig, S.; Hardie, D.; Chrispeels, M.J.; Spencer, D.; Higgins, T.J.V. Bean a-amylase inhibitor confers resistance to the pea weevil, Bruchus pisorum, in genetically engineered peas (Pisum sativum L.). Plant Physiol. 1995, 107, 1233-1239. [CrossRef] [PubMed]

35. Morton, R.L.; Schroeder, H.E.; Bateman, K.S.; Chrispeels, M.J.; Armstrong, E.; Higgins, T.J.V. Bean $\alpha$-amylase inhibitor- I in transgenic peas (Pisum sativum) provides complete protection from pea weevil (Bruchus pisorum) under field conditions. Proc. Natl. Acad. Sci. USA 2000, 97, 3820-3825. [CrossRef] [PubMed] 
36. Queensland Government Department of Primary Industries and Fisheries Guideline, Insects Understanding Helicoverpa Ecology and Biology in Southern Queensland: Know the Enemy to Manage It Better; DPI \& F Information series; ISSN 0727-6273. QI07078 Agdex No. 612; Queensland, Australia, 2005. Available online: https: //www.daf.qld.gov.au/_data/assets/pdf_file/0005/72689/Insects-Helicoverpa-ecology-biology.pdf (accessed on 3 April 2020).

37. Wu, Y.; Mirzaei, M.; Pascovici, D.; Haynes, P.A.; Atwell, B.J. Proteomes of Leaf-Growing Zones in Rice Genotypes with Contrasting Drought Tolerance. Proteomics 2019, 19. [CrossRef] [PubMed]

38. The UniProt Consortium. Available online: https://www.uniprot.org/ (accessed on 19 July 2019).

39. Singh, F.; Oswalt, D. Pigeonpea Botany and Production Practices; International Crops Research Institute for the Semi-Arid Tropics: Hyderabad, India, 1992.

40. Ferguson, A.R. The need for characterisation and evaluation of germplasm: Kiwifruit as an example. Euphytica 2007, 54, 371-382. [CrossRef]

41. Peter, A.J.; Shanower, T.; Romeis, J. The role of plant trichomes in insect resistance: A selective review. Phytophaga 1995, 7, 41-64.

42. Green, P.; Stevenson, P.; Simmonds, M.; Sharma, H. Can larvae of the pod-borer, Helicoverpa armigera (Lepidoptera: Noctuidae), select between wild and cultivated pigeonpea Cajanus sp. (Fabaceae)? Bull. Entomol. Res. 2002, 92, 45-52. [CrossRef]

43. Bisen, S.; Sheldrake, A. The anatomy of the pigeonpea. ICRISAT Res. Bull. 1981, 5, 1-24.

44. Sujana, G.; Sharma, H.; Rao, D.M. Antixenosis and antibiosis components of resistance to pod borer Helicoverpa armigera in wild relatives of pigeonpea. Int. J. Trop. Insect Sci. 2008, 28, 191-200. [CrossRef]

45. Green, P.W.; Stevenson, P.C.; Simmonds, M.S.; Sharma, H.C. Phenolic compounds on the pod-surface of pigeonpea, Cajanus cajan, mediate feeding behavior of Helicoverpa armigera larvae. J. Chem. Ecol. 2003, 29, 811-821. [CrossRef]

46. Simmonds, M.S.; Stevenson, P.C. Effects of isoflavonoids from Cicer on larvae of Heliocoverpa armigera. J. Chem. Ecol. 2001, 27, 965-977. [CrossRef]

47. Haq, S.K.; Khan, R.H. Characterization of a proteinase inhibitor from Cajanus cajan (L.). J. Prot. Chem. 2003, 22, 543-554. [CrossRef]

48. Shade, R.E.; Schroeder, H.E.; Pueyo, J.J.; Tabe, L.M.; Murdock, L.L.; Higgins, T.J.; Chrispeels, M.J. Transgenic pea seeds expressing the $\alpha$-amylase inhibitor of the common bean are resistant to bruchid beetles. Biotechnology 1994, 12, 793. [CrossRef]

49. Swathi, M.; Lokya, V.; Swaroop, V.; Mallikarjuna, N.; Kannan, M.; Dutta-Gupta, A.; Padmasree, K. Structural and functional characterization of proteinase inhibitors from seeds of Cajanus cajan (cv. ICP 7118). Plant Physiol. Biochem. 2014, 83, 77-87. [CrossRef] [PubMed]

50. Prasad, E.R.; Gupta, A.D.; Padmasree, K. Insecticidal potential of Bowman-Birk proteinase inhibitors from red gram (Cajanus cajan) and black gram (Vigna mungo) against lepidopteran insect pests. Pestic. Biochem. Physiol. 2010, 98, 80-88. [CrossRef]

51. Tanksley, S.D.; McCouch, S.R. Seed banks and molecular maps: Unlocking genetic potential from the wild. Science 1997, 277, 1063-1066. [CrossRef]

52. Dodia, D.; Shukla, Y.; Parmar, L.; Tikka, S. Antibiosis-a resistance mechanism governed by antinutritional factors of pigeonpea and its wild relatives against Helicoverpa armigera. Indian J. Pulses Res. 2005, 18, 258.

53. Mallikarjuna, N. Wide hybridization in important food legumes. In Improvement Strategies of Leguminosae Biotechnology; Jaiwal, P.K., Singh, R.P., Eds.; Springer: Dordrecht, The Netherlands, 2015.

54. Srivastava, N.; Vadez, V.; Upadhyaya, H.; Saxena, K. Screening for intra and inter specific variability for salinity tolerance in pigeonpea (Cajanus cajan) and its related wild species. J. SAT Agric. Res. 2006, 2, 1-12.

(C) 2020 by the authors. Licensee MDPI, Basel, Switzerland. This article is an open access article distributed under the terms and conditions of the Creative Commons Attribution (CC BY) license (http://creativecommons.org/licenses/by/4.0/). 